\title{
DESEMPENHO PRODUTIVO E RENDIMENTO DE CARCAÇA DE FRANGOS CRIADOS EM DIFERENTES MATERIAIS DE CAMA AVIÁRIA
}

\author{
PRODUCTIVE PERFORMANCE AND CARCASS YIELD OF BOILERS REARED \\ ON DIFFERENT MATERIALS OF POULTRY LIITTER
}

\author{
Daniela Aguiar Penha Brito ${ }^{1}$ \\ Danilo Rodrigues Barros Brito ${ }^{1 *}$ \\ Antônia Mara Nascimento Gomes ${ }^{1}$ \\ Anadine dos Santos Cunha ${ }^{1}$ \\ Ubirajara Albuquerque Silva Filho ${ }^{1}$ \\ Antônio Anísio Pinheiro ${ }^{1}$ \\ ${ }^{1}$ Instituto Federal do Maranhão, São Luis, MA, Brasil. \\ *Autor para contato - danielabrito@ifma.edu.br
}

\begin{abstract}
Resumo
A cama de aviário é um aspecto de enorme relevância para a avicultura de corte, por influenciar tanto no desempenho zootécnico das aves como nas características de carcaça. Este trabalho objetivou avaliar o desempenho produtivo e o rendimento de carcaça e de vísceras de frangos criados em diferentes materiais de cama aviária. No experimento, foram avaliados 192 pintos, da linhagem Ag Ross, a partir dos 10 dias de vida, distribuídos em 16 unidades experimentais, com 12 aves em cada parcela. Os tratamentos consistiram de quatro materiais de cama (maravalha, capim elefante seco, casca de arroz e areia), com quatro repetições cada. Aos 42 dias de vida, as aves foram pesadas, abatidas e evisceradas. Foram calculados os parâmetros de peso médio, ganho de peso, consumo alimentar, conversão alimentar, viabilidade, rendimento de carcaça e das vísceras comestíveis (coração, moela e fígado). Entre os materiais de cama testados, não houve diferenças significativas nos parâmetros avaliados, porém o ganho de peso das aves criadas em cama de areia foi significativamente superior em relação às aves criadas em cama de capim elefante seco. Concluiu-se que a maravalha, a casca de arroz, o capim elefante seco e a areia podem ser usados como material de cama aviária para frangos de corte sem influenciar no desempenho produtivo e nos rendimentos de carcaça e vísceras comestíveis. Palavras-chave: areia; cama aviária; frango; peso; rendimento de carcaça.
\end{abstract}

\begin{abstract}
The litter is an aspect of great importance for poultry production because it affects both birds's performance and carcass characteristics. This study aimed to evaluate performance and carcass and viscera yields of broilers raised on different materials of poultry litter. In the experiment, we used 192 chicks of Ag Ross strain, from 10 days of age, distributed into 16 experimental units, with 12 birds each plot. Treatments consisted of four bedding materials (wood shavings, dry elephant grass, rice husk and sand), with four replicates each. At 42 days of age, birds were weighed, slaughtered and eviscerated. Then, we calculated the parameters of weight, weight gain, feed intake, feed conversion, viability, carcass and viscera yield (heart, gizzard and liver). Among the bedding materials tested, there were no significant differences in parameters; however, weight gain of birds reared on sand was significantly higher compared to birds reared on dry elephant grass bed. In conclusion, wood shavings, rice husk, dry elephant grass, and sand may be used as litter material for broilers without affecting the productive performance and the yield of carcass and edible offal.
\end{abstract}


Keywords: carcass yield; chicken; poultry litter; sand; weight.

Enviado em: 20 outubro 2012

Aceito em: 10 setembro 2015

\section{Introdução}

A avicultura de corte é um setor agropecuário de grande crescimento e o Brasil se destaca como o maior exportador da carne de frango no mundo $^{(1)}$. A exploração avícola brasileira configura-se como uma das mais desenvolvidas e tecnificadas do mundo, o que credencia o manejo adotado no país como um modelo de sucesso ${ }^{(2)}$.

Para se produzir um frango cada vez mais precoce e se obter maior lucratividade, a avicultura de corte tem exigido a associação de um manejo aprimorado com baixos custos de produção. Nesse contexto, a cama aviária tem relevância, visto que seu manejo correto é fundamental para a obtenção de animais saudáveis com bom desempenho zootécnico, influenciando na qualidade final da carcaça e interferindo nos lucros dos produtores e integradores ${ }^{(3)}$.

Segundo Ávilla et al. ${ }^{(4)}$, a cama aviária consiste de um substrato para absorção da água, incorporação de fezes, urina, penas, descamações da pele e restos de alimento caídos dos comedouros, usado sobre o piso dos aviários. A sua finalidade é absorver a umidade do ambiente e evitar o contato direto das aves com o piso, proporcionando um leito sobre o qual as aves possam permanecer confortavelmente ${ }^{(5)}$. A cama pode ser composta de diferentes tipos de materiais, porém eles precisam apresentar alta capacidade de absorção e liberação de umidade, ser bons isolantes térmicos, liberar pouca quantidade de poeira, ter baixo custo e ser de fácil obtenção( ${ }^{(6)}$.

No Brasil, a maravalha ou cepilho de madeira consolidou-se como o material mais utilizado para cama em criações brasileiras. No entanto, ao longo do tempo, esse material tornou-se escasso e com mais valor de mercado, consequentemente, aumentando o seu custo ${ }^{(7)}$. Vários trabalhos têm sido conduzidos para avaliar diferentes tipos de materiais para uso em aviários, em substituição aos tradicionalmente usados. Os subprodutos agroindustriais (casca de arroz, bagaço de cana, serragem, bagana de carnaúba, casca de café), restos de culturas (sabugo de milho triturado, resíduo de cultura de girassol, palhada de soja picada) e fenos de gramíneas (capim camerom picado, feno de braquiária) têm sido estudados quanto ao seu efeito sobre o desempenho dos frangos de corte $^{(7,8-11)}$ e sobre o rendimento de carcaça e vísceras ${ }^{(11,12)}$.

Os resíduos agrícolas podem ser excelentes alternativas de materiais de cama aviária, principalmente se apresentarem alta disponibilidade regional, baixo custo e se influenciarem positivamente o desempenho zootécnico das aves. Um empecilho para o uso de materiais regionais por criadores de frango de corte, muitas vezes, é a carência de conhecimento técnico e científico quanto ao seu uso. Assim, verificando a importância de se buscarem tipos alternativos de materiais de cama de aviário, assim como a escassez de estudos sobre a influência desses materiais na qualidade da carcaça e das vísceras, este trabalho foi realizado para avaliar o desempenho zootécnico e o rendimento da carcaça e de vísceras comestíveis de frangos de corte criados em cama de maravalha, casca de arroz, feno de capim elefante e areia.

\section{Material e Métodos}

Este experimento foi aprovado pelo Comitê de Ética no Uso Animal (CEUA) do Instituto Federal do Maranhão - IFMA, sob protocolo de n ${ }^{\circ}$. 23249.044707.2015-13 e parecer de número 004/2016.

A pesquisa foi realizada no setor de avicultura de corte do Instituto Federal de Educação, Ciência e Tecnologia do Maranhão (IFMA), Campus São Luís - Maracanã, no município de São Luís- MA. Em um galpão experimental, foram recebidos 192 pintinhos, machos e fêmeas, da linhagem AG ROSS, com 10 dias de idade e com peso médio de 267,4 $\pm 4,5 \mathrm{~g}$. As aves foram pesadas e distribuídas, aleatoriamente, em unidades experimentais constituídas de 16 boxes, com área de $2,5 \mathrm{~m}^{2}(2,5 \times 1,0)$ 
cada, sendo a estrutura de madeira e alvenaria, com tela galvanizada e piso de cimento. Cada boxe foi equipado com um bebedouro pendular e um comedouro tubular automático com capacidade para 25 kg de ração.

Nas unidades experimentais, foram utilizadas a maravalha (tratamento 1), o feno de capim elefante (tratamento 2), a casca de arroz (tratamento 3) e a areia de rio (tratamento 4) como materiais de cama, em altura media de $10 \mathrm{~cm}$. O delineamento experimental foi inteiramente ao acaso sendo as aves distribuídas em quatro tratamentos e quatro repetições de 12 aves cada, totalizando 16 parcelas com 192 frangos.

A maravalha e a areia de rio foram obtidas em madeireiras e estabelecimentos de materiais de construção, respectivamente, do município de São Luís. O capim elefante foi colhido na Fazenda Escola do IFMA, campus Maracanã, triturado em tamanho de 0,6 a 1,2 cm, em trituradora, e seco à sombra, por 72 horas. A casca de arroz foi obtida por doação de uma indústria beneficiadora de arroz na cidade de Itapecuru-Mirim - MA.

Durante o experimento, as aves foram vacinadas, aos 11 dias de idade, contra as doenças de Newcastle, Gumboro e Bronquite Infecciosa por via intraocular. Foram utilizadas 20 horas de iluminação (natural + artificial), água e ração à vontade, além de dietas a base de milho, farelo de soja e suplementos com aminoácidos sintéticos, vitaminas e minerais. O programa de alimentação consistiu de três tipos de ração: inicial (10 a 21dias), crescimento (22 a 35 dias) e final (36 a 42 dias).

Realizou-se a pesagem das rações e das aves no décimo e $42^{\circ}$ dia de idade para a determinação do peso final, ganho de peso, consumo de ração e conversão alimentar. Diariamente, o número de aves mortas foi registrado para a determinação da taxa de sobrevivência.

Aos 42 dias de vida, os frangos foram submetidos ao jejum alimentar pré-abate por seis horas. Após esse período, quatro aves de cada unidade experimental, sendo dois machos e duas fêmeas, foram capturadas, identificadas e transportadas em gaiolas de contenção até o abatedouro de aves do IFMA, campus São Luís - Maracanã. As aves foram pesadas individualmente, sacrificadas por deslocamento cervical e, então, sangradas, escaldadas a $52^{\circ} \mathrm{C}$ por 2 minutos e depenadas. As carcaças das aves foram pesadas e foi realizada a evisceração e retirada da cabeça, do pescoço e dos pés. Para a determinação do rendimento, as carcaças evisceradas sem pés, cabeça e pescoço foram pesadas em balança de precisão. O peso obtido foi dividido pelo peso corporal da ave depois do jejum. O coração e o fígado foram pesados imediatamente após sua retirada, enquanto a moela foi aberta e pesada após remoção do conteúdo e da gordura circundante. O rendimento das vísceras foi determinado em relação ao peso da carcaça depenada.

Os resultados foram submetidos à analise de variância com o auxilio do programa estatístico InStat (Graphpad Instat: GraphPad Software Oberlin, San Diego-CA, USA) e as médias foram comparadas pelo teste de Turkey a 5\% de probabilidade $^{(13)}$.

\section{Resultados e Discussão}

Não foram observadas diferenças $(\mathrm{P}>0,05)$ nos parâmetros de peso médio, consumo de ração, conversão alimentar e taxa de sobrevivência entre os diferentes materiais de cama (Tabela 1), podendose inferir que o feno de capim elefante, a casca de arroz e a areia possibilitaram o mesmo conforto às aves criadas que a maravalha. Houve diferença entre as aves criadas sobre areia e sobre feno para peso corporal e ganho de peso.

Diferenças foram encontradas apenas no peso corporal e ganho de peso das aves criadas em areia, que foi maior dos que as aves criadas em feno de capim elefante em $14 \%(\mathrm{P}>0,05)$. O maior ganho de peso dos frangos criados em areia pode ser atribuído ao comportamento das aves de ingerir os grãos, ao longo do dia. Quando ingeridas, as partículas de areia acumulam-se na moela das aves, diminuindo a taxa de passagem dos alimentos. Esse processo aumenta o tempo de exposição da ração à atividades das enzimas digestivas, melhorando a digestibilidade dos alimentos e, consequentemente, aumentando o ganho de peso dos frangos de corte ${ }^{(11)}$. 
Tabela 1. Desempenho produtivo de frangos (média \pm desvio padrão) criados em cama aviária de diferentes materiais

\begin{tabular}{lccccc}
\hline Tratamentos & $\begin{array}{c}\text { Peso } \\
\text { Corporal } \\
\mathbf{( g )}\end{array}$ & $\begin{array}{c}\text { Ganho de } \\
\text { Peso } \\
(\mathbf{g})\end{array}$ & $\begin{array}{c}\text { Consumo de } \\
\text { ração } \mathbf{( g )}\end{array}$ & $\begin{array}{c}\text { Conversão } \\
\text { alimentar }\end{array}$ & $\begin{array}{c}\text { Taxa de } \\
\text { sobrevivência } \\
(\%)\end{array}$ \\
\hline Maravalha & $2370,80 \pm$ & $2116,30 \pm$ & $4254,10 \pm$ & $2,01 \pm 0,07 \mathrm{a}$ & $100 \pm 0,0 \mathrm{a}$ \\
Feno de capim & $161,4 \mathrm{ab}$ & $167,9 \mathrm{ab}$ & $276,4 \mathrm{a}$ & & \\
elefante & $2264,50 \pm$ & $1999,57 \pm$ & $4217,70 \pm$ & $2,11 \pm 0,01 \mathrm{a}$ & $100 \pm 0,0 \mathrm{a}$ \\
Casca de arroz & $76,5 \mathrm{a}$ & $73,4 \mathrm{a}$ & $144,5 \mathrm{a}$ & & \\
& $2381,20 \pm$ & $2115,24 \pm$ & $4291,60 \pm$ & $2,03 \pm 0,04 \mathrm{a}$ & $100 \pm 0,0 \mathrm{a}$ \\
Areia & $70,1 \mathrm{ab}$ & $73,9 \mathrm{ab}$ & $227,0 \mathrm{a}$ & & \\
& $2547,10 \pm$ & $2279,00 \pm$ & $4560,40 \pm$ & $2,00 \pm 0,06 \mathrm{a}$ & $97,91 \pm 4,2 \mathrm{a}$ \\
& $105,4 \mathrm{~b}$ & $105,4 \mathrm{~b}$ & $239,4 \mathrm{a}$ & & \\
\hline
\end{tabular}

Médias com letras iguais, na coluna, não diferem entre si pelo Teste de Tukey $(P>0,05)$.

O menor ganho de peso observado em aves criadas em cama de feno de capim elefante em relação à areia pode estar relacionado ao comportamento das aves de passar maior período do dia em descanso sob esse tipo de cama, fato observado durante o experimento. O maior tempo de descanso das aves pode ter levado ao menor interesse em se alimentarem nos comedouros.

Santos et al. ${ }^{(10)}$ e Araújo et al. ${ }^{(14)}$ realizaram pesquisas com o feno de capim elefante, a casca de arroz e a maravalha como cama aviária e não constataram diferenças no consumo alimentar e na conversão alimentar das aves. Porém, em relação à areia, Atencio et al. ${ }^{(11)}$ encontraram resultado diferente, pois verificaram maior consumo alimentar de frangos criados em cama de areia em relação à maravalha, casca de arroz e areia misturada com maravalha. Em uma pesquisa avaliando o desempenho de frangos de corte criados em cama de areia e de maravalha, Bilgili et al. ${ }^{(15)}$ encontraram maior peso corporal e maior consumo de ração de frangos machos criados em areia em relação à maravalha.

Verificou-se que os frangos criados em cama de maravalha apresentaram maior rendimento de carcaça $(75,09 \%)$; entretanto, não apresentaram diferenças significativas nos outros tratamentos $(\mathrm{P}>0,05)$ (Tabela 2). O rendimento das vísceras comestíveis também não apresentou diferenças; portanto, não foram influenciadas pelos diferentes tipos de materiais de cama. Esses resultados estão de acordo aos encontrados por Demirulus ${ }^{(16)}$, que não encontraram diferença significativa sobre o rendimento de vísceras comestíveis entre frangos criados em cama de palha e cepilho de madeira. Toghyani ${ }^{(17)}$ constataram que a cama do tipo maravalha, casca de arroz e areia não influenciaram no rendimento de carcaça e de moela de frangos de corte.

Tabela 2: Rendimento de carcaça e de vísceras dos frangos de corte (média \pm desvio padrão) criados em diferentes tipos de cama de aviário

\begin{tabular}{lcccc}
\hline \multirow{2}{*}{ Tratamentos } & Carcaça & Coração & Moela & Figado \\
\cline { 2 - 5 } Maravalha & $75,09 \pm 3,8$ & $0,46 \pm 0,1$ & $1,26 \pm 0,1$ & $1,53 \pm 0,2$ \\
Capim elefante seco & $74,67 \pm 0,6$ & $0,42 \pm 0,04$ & $1,45 \pm 0,1$ & $1,59 \pm 0,2$ \\
Casca de arroz & $74,93 \pm 1,4$ & $0,40 \pm 0,04$ & $1,36 \pm 0,06$ & $1,56 \pm 0,2$ \\
Areia & $73,90 \pm 1,4$ & $0,45 \pm 0,06$ & $1,33 \pm 0,1$ & $1,62 \pm 0,2$ \\
\hline
\end{tabular}

O rendimento de carcaça e de vísceras é um parâmetro importante para a indústria de alimentos, pois representa a quantidade comestível do produto e o que de fato se comercializa no mercado. Verificouse que os materiais de cama avaliados não afetaram os rendimentos de carcaça, coração, moela e fígado das aves. Isso sugere que a seleção de um desses materiais não influenciará nas características qualitativas e quantitativas da porção comestível do produto, evitando prejuízos para a indústria de produção de carne de aves.

Apesar de a areia não ser um material comumente usado como cama aviária no Brasil, esse material 
mostrou-se equivalente em relação aos tradicionalmente utilizados como a maravalha e a casca de arroz para desempenho produtivo e rendimento de carcaça e vísceras. Portanto, a escolha de um desses materiais depende da disponibilidade e do preço do produto na região, assim como na finalidade de sua utilização após o descarte.

\section{Conclusão}

Concluiu-se que a maravalha, a casca de arroz e a areia podem ser usados como material de cama aviária para frangos de corte sem influenciar no desempenho produtivo e no rendimento de carcaça e vísceras comestíveis.

\section{Referências}

1. ABPA, Associação Brasileira de Proteína Animal, 2014 [cited 2014 apr 28]. Available from: http://abpa-br. com.br/setores/avicultura/mercado-mundial. Portuguese.

2. Ávilla VS, Costa CAF, Figueiredo EAP, Rosa OS, Oliveira U, Abreu VMN. Materiais alternativos, em substituição a maravalha como cama de frango. n465. Brasília: Embrapa, Comunicado Técnico; 2007. 5p. Portuguese. Disponível em http://ainfo.cnptia.embrapa.br/digital/bitstream/item/58061/1/ CUsersPiazzonDocuments465.pdf

3. Fiorentin L. Reutilização da cama na criação de frangos e as implicações de ordem bacteriológica na saúde humana e animal. n94. Concórdia: Embrapa Suínos e Aves; 2005. 23p. Portuguese. Disponível em: https:// www.infoteca.cnptia.embrapa.br/infoteca/bitstream/doc/443593/1/doc94.pdf

4. Ávilla MAC, Mazzuco H, Figueiredo EAP. Cama de aviário: materiais, reutilização, uso como alimento e fertilizante. n16. Brasília: Embrapa, Circular Técnica; 1992.38p. Portuguese. Disponível em: http://ainfo.cnptia. embrapa.br/digital/bitstream/item/67877/1/CUsersPiazzonDocumentsProntosCNPSA-DOCUMENTOS-16CAMA-DE-AVIARIO-MATERIAIS-REUTILIZACAO-USO-COMO-ALIMENTO-E-FERTILIZANTEFL-12.pdf

5. Cotta T. Frangos de corte: criação, abate e comercialização. Viçosa: Aprenda Fácil Editora; 2008. 250p. Portuguese.

6. Gewehr CE. Cama de aviário de capim elefante. Revista Agropecuária Catarinense. 2003; 16(1):38-42.

7. Ávilla VS, Oliveira U, Figueiredo AP, Costa CAF, Abreu VMN, Rosa PS. Avaliação de materiais alternativos em substituição à maravalha como cama de aviário. Revista Brasileira de Zootecnia. 2008;37(2):273-277.

8. Azevedo AR, Costa AM, Alves AA, Garcia CP, Bastos FJS, Barreto CM. Desempenho produtivo de corte da linhagem Hubbard criados sobre diferentes tipos de cama. Revista Científica de Produção Animal. 2000;2(1):52-57.

9. Neme R, Sakomura NK, Oliveira MDS, Longo FA, Figueiredo AN. Adição de gesso agrícola em três tipos de cama de aviário na fixação do nitrogênio e no desempenho do frango de corte. Ciência Rural. 2000;30(4):687692.

10. Santos EC, Cotta JTB, Muniz JA, Fonseca RA, Torres DM. Avaliação de alguns materiais usados como cama sobre o desempenho de frangos de corte. Ciência Agrotec. 2000;14(4): 1024-1030.

11. Atencio JL, Fernández JA, Gernat AG, Murillo JG. Effect of pine woods shavings, rice hulls and river bed sand on broiler productivity when used as a litter sources. Int J Poult Sci. 2010;3 (9):240-243.

12. Oliveira MC, Carvalho ID. Rendimento e lesões em carcaças de frangos de corte criados em diferentes camas e densidades populacionais. Ciência e Agrotecnologia. 2002;26(5):1076-1081. 
13. Pimentel-Gomes F. Curso de estatística experimental. 12ed. Piracicaba: Nobel; 1987. 467p. Portuguese.

14. Araujo JS, Oliveira V, Braga GC. Desempenho de frangos de corte criados em diferentes tipos de cama e taxa de lotação. Ciência Animal Brasileira. 2007;8(1):59-64.

15. Bilgili SFGI, Montenegro JB, Hess MK, Eckman. Live performance, carcass quality, and deboning yields of broilers reared on sand as a litter source. J Appl Poult Res. 1999;8(1):352-361.

16. Demirulus H. The Effect of Litter Type and Litter Thickness on Broiler Carcass Traits. International Journal of Poultry Science. 2006;7(5):670-672.

17. Toghyani M, Gheisari A, Modaresi M, Tabeidian SA, Toghyani M. Effect of different litter material on performance and behavior of broiler chickens. Applied Animal Behaviour Science. 2010;122 (1):48-52. 